Working Paper/Document de travail

2007-39

\title{
Liquidity, Redistribution, and the Welfare Cost of Inflation
}

by Jonathan Chiu and Miguel Molico 
Bank of Canada Working Paper 2007-39

July 2007

\title{
Liquidity, Redistribution, and the Welfare Cost of Inflation
}

\author{
by \\ Jonathan Chiu and Miguel Molico \\ Monetary and Financial Analysis Department \\ Bank of Canada \\ Ottawa, Ontario, Canada K1A 0G9 \\ jchiu@bankofcanada.ca \\ mmolico@bankofcanada.ca
}

Bank of Canada working papers are theoretical or empirical works-in-progress on subjects in economics and finance. The views expressed in this paper are those of the authors.

No responsibility for them should be attributed to the Bank of Canada. 


\section{Acknowledgements}

We have benefited from the comments and suggestions of participants at the CEA meetings in Montreal, the Money, Banking and Payments Workshops at the Cleveland Fed, Midwest Macroeconomics conference in St. Louis, the SED conference in Vancouver, and the Dynamic Models Useful for Policy Making conference at the Bank of Canada. Special thanks are due to Jeannie Kottaras for her assistance with Canadian monetary aggregates' data and to Steve Ambler, Walter Engert, Cesaire Meh, and Randall Wright for their comments on an earlier draft of this paper. 


\begin{abstract}
This paper studies the long run welfare costs of inflation in a micro-founded model with trading frictions and costly liquidity management. Agents face uninsurable idiosyncratic uncertainty regarding trading opportunities in a decentralized goods market and must pay a fixed cost to rebalance their liquidity holdings in a centralized liquidity market. By endogenizing the participation decision in the liquidity market, this model endogenizes the responses of velocity, output, the degree of market segmentation, as well as the distribution of money. We find that, compared to the traditional estimates based on a representative agent model, the welfare costs of inflation are significantly smaller due to distributional effects of inflation. The welfare cost of increasing inflation from $0 \%$ to $10 \%$ is $0.62 \%$ of income for the U.S. economy and $0.20 \%$ of income for the Canadian economy. Furthermore, the welfare cost is generally non-linear in the rate of inflation, depending on the endogenous responses of the liquidity market participation to inflation and liquidity management costs.
\end{abstract}

JEL classification: E40, E50

Bank classification: Inflation: costs and benefits

\title{
Résumé
}

Les auteurs étudient les coûts à long terme de l'inflation au plan du bien-être dans un modèle avec fondements microéconomiques où les échanges s'accompagnent de frictions et d'une gestion des liquidités coûteuse. Les agents sont confrontés à une incertitude idiosyncratique inassurable qui touche les occasions d'échange sur un marché décentralisé des biens, et ils doivent rééquilibrer leurs avoirs liquides à coût fixe sur un marché centralisé des liquidités. En conférant un caractère endogène à la décision des agents de participer au marché des liquidités, les auteurs permettent au modèle d'endogénéiser les réactions obtenues pour la vitesse de circulation, la production, le degré de segmentation des marchés et la distribution de la monnaie. Ils constatent que, par rapport aux estimations conventionnelles des modèles à agent représentatif, les coûts de l'inflation sur le bien-être se trouvent nettement réduits par les effets de répartition de l'inflation. Ainsi, la hausse du taux d'inflation de 0 à $10 \%$ se solde, en termes de bien-être, par une perte de revenus de $0,62 \%$ pour l'économie américaine et de $0,20 \%$ pour l'économie canadienne. De plus, la perte de bien-être n'évolue souvent pas dans les mêmes proportions que le taux d'inflation, mais dépend de l'effet endogène qu'a l'inflation sur la participation au marché des liquidités ainsi que des frais de gestion des liquidités.

Classification JEL : E40, E50

Classification de la Banque : Inflation : coûts et avantages 


\section{Introduction}

The adoption of formal inflation targets by Canada and other countries during the last decades and the generalized move towards lower inflation by most countries has stimulated a considerable interest in the welfare gains from price stability. In this paper, we contribute to this debate by evaluating the long-run welfare costs of inflation in a micro-founded monetary model with trading frictions, modeled as uninsurable idiosyncratic uncertainty regarding trading opportunities, and costly liquidity management.

The measurement of the welfare costs of inflation is one of the classic questions in monetary economics and has been addressed in a long line of research starting with the contributions of Bailey (1956) and Friedman (1969). In his seminal paper, Bailey proposed quantifying the welfare cost of inflation by measuring the "welfare triangle," the area under the money demand curve representing the consumers' surplus that could be gained by reducing the nominal interest rate from $r$ to zero. In a recent paper, Lucas (2000) surveys research on the welfare cost of inflation and provides new estimates for the U.S. economy. Lucas estimates the welfare gain of going from $10 \%$ to $0 \%$ inflation to be slightly below 1 percent of income. The magnitude of the estimate of such costs is not without controversy and, in particular, depends critically on the interest and transaction sensitivity of the money demand. ${ }^{1}$ Given that there are few historical episodes of very low and very high nominal interest rates for which data is available, the robust estimation of such critical parameters as the interest elasticity of the money demand becomes particularly challenging. Guidance from solid micro-founded monetary theory becomes essential to understand how individuals manage their liquidity. In Lucas' own words, "[...] theory at the level of the models I reviewed [...] is not adequate to let us see how people would manage their cash holdings at very low interest rates. Perhaps for this purpose theories that take us farther on the search for foundations, such as the matching models introduced by Kiyotaki and Wright, are needed."

\footnotetext{
${ }^{1}$ Lucas' estimate is double the estimates of Bailey's and others. The reason for these higher costs is that Lucas uses a double log schedule for the money demand, as opposed to the semi-log schedule utilized by Bailey and Friedman, arguing that it provides a better fit to twentieth-century U.S. data.
} 
In this paper we pursue exactly this challenge.

A recent paper by Lagos and Wright (2005) proposes a new framework for monetary and policy analysis based on a micro-founded search theoretical model of money and provides new measures of the welfare costs of inflation. They calibrate their model to match the U.S. empirical money demand curve and find a much higher welfare cost than standard estimates. Their model predicts that going from $10 \%$ to $0 \%$ inflation can be worth between $3 \%$ and $5 \%$ of consumption. The reason for these higher welfare costs are the distortions (holdup problems) introduced by the non-competitive pricing mechanism assumed - generalized Nash-bargaining. In the absence of these distortions, e.g., when buyers get to make take-itor-leave-it offers to sellers, their estimates are similar to those of Lucas. ${ }^{2}$

One limitation of the analysis conducted by Lagos-Wright is that, for the sake of analytical tractability, they make restrictive assumptions that eliminate some of the most interesting features of standard search models of money, features that could have important implications for the measurement of the welfare costs of inflation. In particular, in standard search models uninsurable idiosyncratic uncertainty regarding trading opportunities, and thus the timing and amounts of receipts and disbursements of money (an empirically plausible feature), leads to a non-trivial liquidity management problem and, in equilibrium, to a non-degenerate distribution of money across agents. In such an environment, agents hold money for both transactions and precautionary motives and an expansionary redistributive monetary policy can potentially be welfare improving by providing "insurance" against an agent's idiosyncratic trading history. ${ }^{3}$ On the other hand, Lagos and Wright allow agents

\footnotetext{
${ }^{2}$ In their model agents must make an irreversible decision, while in a centralized market, on how much money to bring into the bargaining table in the decentralized market. The more money an agents brings the bigger the surplus of trade to be had at a bilateral meeting. Yet, unless the buyer has all the bargaining power, he will only get part of that additional surplus. As such, agents will generally bring too little money into the decentralized market. Inflation, by decreasing the amount of real money balances agents want to carry in equilibrium, further accentuates this distortion leading to the higher welfare costs of inflation.

${ }^{3}$ For example, see Deviatov and Wallace (2001) and Molico (2006). Similar results are found in Levine (1991), in a distinct environment. In contrast, İmrohoroğlu (1992) finds that, in an endowment economy where agents hold money in order to smooth consumption in the face of income variability for which there is no insurance, the welfare costs of inflation are significantly higher than previous estimates since inflation hinders the ability of agents to smooth consumption.
} 
to costlessly re-balance their money holdings without limit by producing and trading "general goods" in a centralized market after each round of decentralized trade. By assuming agents have quasilinear preferences over such goods they effectively provide a mechanism through which agents can perfectly "insure" against their idiosyncratic trading histories. By construction, this assumption eliminates any redistributive gains from inflation making it impossible to determine if these effects are quantitatively significant. As mentioned above, these assumptions are made for the sake of analytical tractability and not for their empirical plausibility.

Our paper relaxes these assumptions by considering an environment in which the participation in a centralized liquidity market is both costly and endogenous. In particular, we assume that agents have to pay a fixed cost to participate in such a market. ${ }^{4}$ This assumption is meant to capture the idea that participation in organized trading, intermediation and financial market is costly. These costs include not only financial costs of participation but also time spent in such activities. Moreover, it is motivated by the fact that not all households actively and frequently participate in these activities, and that the participation rate depends on the state of the economy (e.g., inflation and financial development). Because of this market participation friction, agents choose to attend the centralized market only infrequently and to keep an inventory of money for trading in the decentralized market. In this sense, our model provides micro-foundations for a class of inventory theoretic monetary models in the tradition of Baumol (1952) and Tobin (1956). ${ }^{5}$ In our model, the centralized market provides only limited "insurance" against idiosyncratic uncertainty. By endogenizing the decision of participation, this model also endogenizes the responses of velocity, output, the degree of market segmentation as well as the monetary distribution. We calibrate the

\footnotetext{
${ }^{4}$ We interpret this market as a "pure liquidity market" in the sense that we assume agents have linear preferences over the goods traded in such market. As such, the only reason an agent would participate in this market would be to re-balance his or her money holdings, given that market participation is costly and there is no other gains of trade to be had. This market is meant to proxy for a number of markets in the actual economy in which agents can obtain insurance against liquidity risk, for example, financial markets.

${ }^{5}$ For general equilibrium versions of inventory theoretic models of money see, for example, Jovanovic (1982) and Romer (1986).
} 
model to match both the U.S. and Canadian empirical money demands and use a numerical algorithm to study the long-run effects of inflation on welfare for both economies.

The costs and benefits of inflation in our model are threefold. First, as is common in most monetary models, inflation serves as a distortionary tax reducing welfare. Second, inflation generates deadweight loss associated with the liquidity management activities. Finally, mildly expansionary redistributive monetary policy can potentially be welfare improving by relaxing the liquidity constraint of some agents. In this way, inflation works as an "insurance" mechanism against an agents's liquidity risk.

Our findings confirm that the consideration of costly liquidity management and distributional effects quantitatively matter for the welfare cost of inflation. First, we find that the welfare cost differs significantly from that of a representative agent model and is not well captured by the area under the aggregate money demand. In particular, abstracting from the hold-up problem mentioned above, the welfare cost is generally lower than the traditional estimates due to the distributional effects of inflation. Namely, for example, we find that the welfare gain of reducing inflation from $10 \%$ to $0 \%$ to be $0.62 \%$ of income for the U.S. economy and $0.20 \%$ of income for the Canadian economy. The corresponding areas under the aggregate money demand curves (which are approximately equal to the welfare cost in a representative agent model) are, respectively, $0.85 \%$ and $0.34 \%$. It is worthwhile noticing that the welfare costs of a $10 \%$ inflation for the Canadian economy is one third of that of the U.S. economy. This finding is consistent with previous estimates of the welfare costs of inflation for both economies using a representative agent models and is a reflection of the lower interest-elasticity of the Canadian money demand implied by the data. Furthermore, as is the case for the U.S. economy, our estimate is lower than previous estimates in the literature. $^{6}$

Second, the welfare cost is generally non-linear in the rate of inflation. The welfare

\footnotetext{
${ }^{6}$ For example, Serletis and Yavari (2004) redo the estimates of Lucas for the Canadian economy using recent advances in the field of econometrics to estimate the interest elasticity of money demand and report a welfare cost of $0.35 \%$ from reducing the nominal interest rate from $14 \%$ to $3 \%$, similar to the area under the demand curve that we estimate.
} 
cost of small rates of inflation might be proportionally smaller or larger than that of higher rates depending on how the participation rate in the liquidity market and associated costs responds to inflation. This implies that the welfare costs of $10 \%$ inflation might not be too informative if one is interested in evaluating the welfare gains of reducing inflation, say, from $2 \%$ to $1 \%$. Moreover, the effect of a decrease in the costs of participation in the liquidity market, say due to financial development, on the welfare cost of different rates of inflation might vary both quantitatively and qualitatively.

This paper is related to other papers in the search-theoretical literature that extend the Lagos and Wright framework by assuming that agents can trade in the centralized market only infrequently. Berentsen, Camera and Waller (2005), Ennis (2005), Williamson (2006), and Telyukova and Wright (2005) study an environment in which agents participate in the centralized market at an exogenous rate. This paper takes a further step to fully endogenize the participation in the centralized market because the participation decision should not be taken as invariant to policy intervention. This paper also generalizes the existing search literature by developing a framework that nests several existing search models as special cases. When the fixed cost is zero, the model reduces to Lagos and Wright (2005) in which the Friedman rule is optimal. When the cost is infinite, the model reduces to Molico (2006) in which positive inflation can be welfare improving. Finally, this paper also contributes to the literature by integrating an endogenous market segmentation model (focusing on market participation frictions) ${ }^{7}$ with a search-theoretic model (focusing on goods trading frictions).

The rest of the paper is organized as follows. Section 2 describes the environment. Section 3 defines an equilibrium. Section 4 discusses the numerical algorithm used to compute the stationary equilibria of the model. In section 5 , to facilitate the comparison of our results to the existing literature, we calibrate the model to match the empirical money demand for the U.S. economy and study the welfare cost of inflation. In section 6 we redo the exercise

\footnotetext{
${ }^{7}$ Models with exogenous market segmentation include Grossman and Weiss (1983), Alvarez and Atkeson (1997), and Alvarez, Atkeson and Edmond (2003). Models with endogenous market segmentation include Alvarez, Atkeson and Kehoe (1999), Chiu (2005) and Khan and Thomas (2005). All these models impose an exogenous cash-in-advance constraint.
} 
for the Canadian economy. Section 7 concludes the paper.

\section{The Model}

Time is discrete and denoted by $t=0,1,2, \ldots$. There are two types of non-storable commodities: general and special goods. The economy consists of a continuum $[0,1]$ of agents. The per-period utility of an agent is given by

$$
U\left(X_{t}\right)-C\left(Y_{t}\right)+u\left(x_{t}\right)-c\left(y_{t}\right)
$$

where $U(X)$ denotes the utility of consuming $X$ units of the general good, $C(Y)$ denotes the disutility of producing $Y$ units of the general good, $u(x)$ denotes the utility of consuming $x$ units of the special good, and $c(y)$ denotes the disutility of producing $y$ units of the special good. We assume that $U(X)=X$ and $C(Y)=Y{ }^{8}$ Also, we assume that $u(\cdot)$ is twice continuously differentiable, strictly increasing, concave (with $u$ strictly concave), and satisfy $u(0)=0$ with $u^{\prime}(\bar{x})=1$ for some $\bar{x}>0$. Also, $c(y)=y$. Agents discount the future at discount factor $\beta \in(0,1)$.

In this economy, there is an additional, perfectly divisible, and costlessly storable object which cannot be produced or consumed by any private individual, called fiat money. Agents can hold any non-negative amount of money $\hat{m} \in \mathbb{R}_{+}$. The money stock at the beginning of period $t$ is denoted $M_{t}$. In what follows we express all nominal variables as fractions of the beginning of the period money supply (before the current period's money transfers which we will describe below), $m \equiv \frac{\hat{m}}{M}$. Let $\nu_{t}: \mathfrak{B}_{\mathbb{R}_{+}} \rightarrow[0,1]$ denote the probability measure associated with the money (as a fraction of the beginning of period money supply) distribution at the

\footnotetext{
${ }^{8}$ The assumption of linear utility will allow us to interpret the general goods market as a "pure liquidity market" in the sense that there is no surplus of trade to be had in such market. As will be shown, the only reason agents participate in that market is to re-balance their money holdings. Under appropriate assumptions to preclude their circulation in the decentralized market, one could introduce nominal bonds in this market and interpret the trades as financial asset trades. In that world, in equilibrium, agents are indifferent between using bonds or trading the general good. In Lagos and Wright, $U(X)-C(Y)$ is quasi-linear.
} 


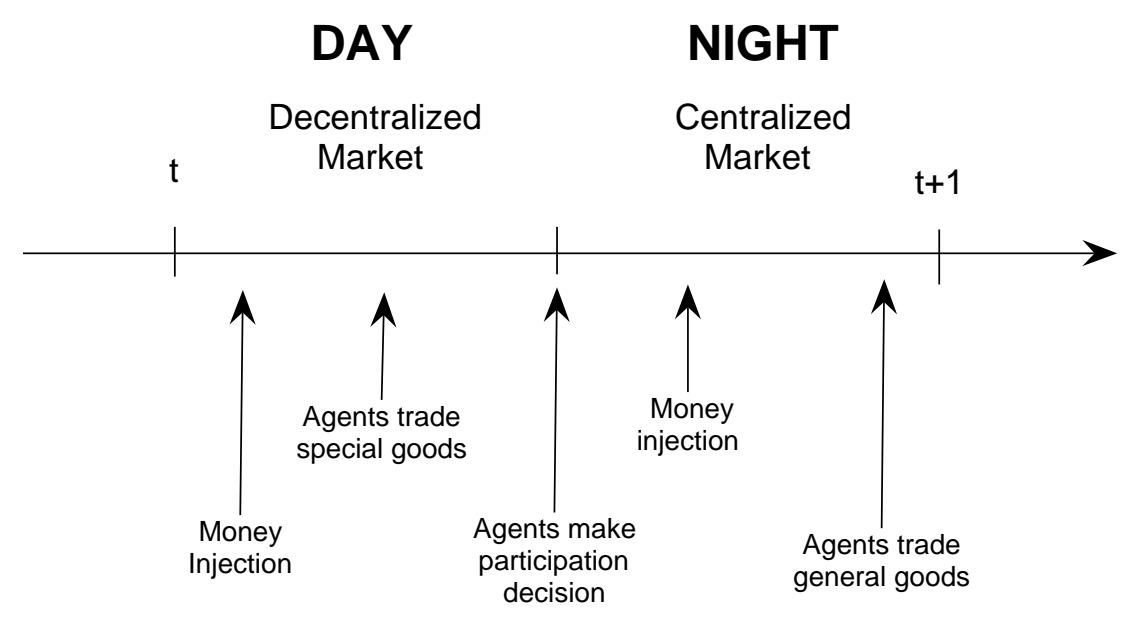

Figure 1: Time line

beginning of period $t$, where $\mathfrak{B}_{\mathbb{R}_{+}}$denotes the Borel subsets of $\mathbb{R}_{+}$.

Each period is divided into two subperiods: day and night. In the day time, there is a decentralized market for trading special goods. In the night time, there is a centralized market for trading general goods (see Figure 1).

As in standard search-theoretical models of money, in the decentralized market, agents are subject to trading frictions modeled as pairwise random matching. To generate the need for trade, we assume that agents cannot consume their own production of special goods. To generate the use of money, we assume that the probability of having a double coincidence of wants meeting is zero and that all trading histories are private information. ${ }^{9}$ The probability that an agent consumes something his/her match partner produces is $\sigma \in\left[0, \frac{1}{2}\right]$. Similarly, the probability that an agent produces something that his/her match partner consumes is $\sigma$. Therefore, with a probability $1-2 \sigma$, trading partners do not want each other's goods.

\footnotetext{
${ }^{9}$ For money to be valued it is only required that in some meetings there is no double coincident of wants. For simplicity, we focus on purely monetary trades and, by assumption, preclude the possibility of barter in the decentralized market.
} 
When two individuals meet and one consumes the good the other produces, they bargain over the amount of output and the amount of money to be traded. Let $q_{t}\left(m_{b}, m_{s} ; \nu_{t}\right) \geq 0$ be the amount of output and $d_{t}\left(m_{b}, m_{s} ; \nu_{t}\right) \geq 0$ the amount of money determined by the bargaining process at date $t$ between a buyer with money holdings $m_{b}$ and a seller with $m_{s}$, when the probability measure at the beginning of the period is $\nu_{t}$. In particular, the terms-of-trade are assumed to be determined by take-it-or-leave-it offers by the buyers. ${ }^{10}$ Let $\omega_{t}: \mathfrak{B}_{\mathbb{R}_{+}} \rightarrow[0,1]$ denote the probability measure over money holdings at the entrance of the centralized market (after trade in the decentralized market).

At night after the decentralized market closes, there is a Walrasian market for the general good that opens. Participation in that market is costly. It is assumed that, at the beginning of each night, each agent $i$ draws a random fixed cost $\kappa_{t}^{i}$ (in units of the general good). The cost $\kappa$ is assumed to be i.i.d. across time and agents with uniform distribution over the support $[0, \bar{\kappa}]$. Given the individual's realization of the fixed cost, an agent must decide whether or not to participate in the market. Agents take the price of money in terms of the general good in that market, $\phi_{t}$, as given. If an agent chooses not to participate in the centralized market, he/she consumes zero amount of the general good in autarky. If the agent decides to participate he/she must decide how much of the general good to consume and produce, and how much money holdings to carry into the decentralized market the next day.

Given the environment, the only feasible trades during the day are the exchange of special goods for money and at night barter in general goods or the exchange of general goods for money.

The money stock is assumed to grow at a constant growth rate $\mu=\frac{M_{t}}{M_{t-1}}$ for all $t$. Money growth is accomplished via money transfers at the entrance of the decentralized market. Given the distribution $\nu_{t}$, an agent with money holdings $m$ receives a monetary transfer at

\footnotetext{
${ }^{10}$ More generally, we could consider that the terms of trade were determined by the solution of a generalized Nash-bargaining problem as in Lagos-Wright. As shown in that paper if the seller has some bargaining power additional distortions exist that would imply higher welfare costs of inflation. The same would be true here. In that sense, we provide a lower bound for the welfare costs of inflation.
} 
the beginning of the period $t$ decentralized market, $\tau\left(m, \nu_{t}\right)$ (as in Lagos-Wright or Molico). ${ }^{11}$ We assume that the monetary transfers (monetary policy rule) are such that rate of monetary growth is constant over time.

$$
\mu \equiv \int_{0}^{\infty}\left[m+\tau\left(m, \nu_{t}\right)\right] \nu_{t}(m) d m
$$

This concludes the description of the environment. In what follows, we will gradually build towards the definition of equilibrium.

\section{Equilibrium}

In this section we define a recursive equilibrium for this economy. We begin by describing the individual and aggregate state variables. An individual's state variable consists of his/her money holdings (as a fraction of the beginning of the period money supply). The aggregate state variable is, in turn, defined as the current probability measure over money holdings. Thus, at the beginning of the period an individual's state is described by the pair $(m, \nu)$, and at the entrance of the centralized market by $(m, \omega)$. Agents take as given the law of motion of the aggregate state variable defined by $\nu^{\prime}=H_{\nu}(\omega)$ and $\omega=H_{\omega}(\nu)$ which we will describe in detail below, where prime denotes the future period. ${ }^{12}$ Also, agents take as given the price of money in units of the general good in the centralized market, $\phi$, as a function of the current aggregate state, $\phi: \Lambda \rightarrow \mathbb{R}_{+} \backslash\{0\}$, where $\Lambda$ denotes the space of probability measures over $\mathfrak{B}_{\mathbb{R}_{+}} \cdot{ }^{13}$ Finally, agents take as given the monetary policy rule (transfers) $\tau: \mathbb{R}_{+} \times \Lambda \rightarrow \mathbb{R}$

\footnotetext{
${ }^{11}$ In principle, money could also be injected by transfers to participants in the centralized market. This would generate an additional "limited participation" effect by redistributing wealth from non-participants to participants. We study this case in a separate note.

${ }^{12}$ Equivalently, define the law of motion of by $\nu^{\prime}=H(\nu) \equiv H_{\nu}\left(H_{\omega}(\nu)\right)$.

${ }^{13}$ Note that by restricting $\phi$ to be strictly positive, we focus on only monetary equilibrium in which money has value.
} 


\subsection{The Centralized Market}

For presentation convenience we begin by describing an agent's problem at the entrance of the centralized liquidity market. In what follows we describe the value functions of participants and non-participants in the centralized market, and then step back to examine the entry decision of an agent after the realization of the fixed cost in order to derive the value function at the entrance of the centralized market.

Consider the expected lifetime utility of an agent that after incurring the fixed cost participates in the centralized market, $W^{1}(m, \omega)$, where $m$ is the money balance held by the agent normalized by the beginning-of-the-period money stock. Given the price of money, $\phi(\omega)$, and the monetary policy rules, the value function is given by

$$
\begin{aligned}
& W^{1}(m, \omega)=\max _{X, Y, m^{\prime} \geq 0} X-Y+\beta V\left(m^{\prime}, \nu^{\prime}\right) \\
& \text { s.t. } \\
& Y \geq X+\phi(\omega)\left[m^{\prime} \mu-m\right] \\
& \nu^{\prime}=H_{\nu}(\omega),
\end{aligned}
$$

where $V(m, \nu)$ is the value function for an agent at the beginning of the day with money balances $m$ when the aggregate state is $\nu .{ }^{14}$ Given the individual state $m$ and aggregate state $\omega$, an agent chooses the optimal amounts of the general good consumption $(X)$, the general good production $(Y)$, as well as the money holding at the entrance of the next decentralized market $\left(m^{\prime}\right)$. The linearity of preferences implies that the optimal choice of $(X, Y)$ is not unique but this indeterminancy has no implications for the individual money demand, $m^{\prime}$. Given that we intend this market to proxy for a pure liquidity trading market

\footnotetext{
${ }^{14}$ In what follows, we will assume that $V(\cdot, \omega)$ is a continuous function. By the Theorem of the Maximum, $W^{1}(\cdot, \omega)$ is a continuous function and the set of optimizers is a nonempty, compact-value, and an u.h.c. correspondence. By the Measurable Selection Theorem, define $m^{\prime}(m, \omega)$ to be a measurable section of such correspondence.
} 
(with no value added), we ignore the production and consumption of the general goods in our measure of aggregate output. ${ }^{15}$ The budget constraint simply states that the expenditure on consumption and on net money purchase is no greater than the income from production. We can show that (see Lagos and Wright for details),

$$
W^{1}(m, \omega)=\phi(\omega) m+\max _{m^{\prime}}\left[-\phi(\omega) m^{\prime} \mu+\beta V\left(m^{\prime}, \nu^{\prime}\right)\right]
$$

The expected lifetime utility of an agent not participating in the centralized market with money holding $m$ is given by

$$
W^{0}(m, \omega)=\beta V\left(\frac{m}{\mu}, H_{\nu}(\omega)\right)
$$

Non-participants consume and produce nothing and their money balance (as a fraction of the beginning of the period money supply) declines at the rate of money growth.

We now consider the decision of whether or not to participate in the centralized market. Consider the case of an agent at the entrance of the centralized market with money holdings $m$ when the aggregate state is $\omega$ and who draws a fixed cost $\kappa$. The agent will participate in the centralized market as long as

$$
W^{1}(m, \omega)-\kappa>W^{0}(m, \omega)
$$

Define $\hat{\kappa}(m, \omega)$ to be the threshold value such that any agent with state $(m, \omega)$ that draws a cost $\kappa$ chooses to participate if $\kappa<\hat{\kappa}(m, \omega)$. The threshold function $\hat{\kappa}: \mathbb{R}_{+} \times \Lambda \rightarrow[0, \bar{\kappa}]$ is defined as

$$
\hat{\kappa}(m, \omega)=\min \left\{\max \left\{0, W^{1}(m, \omega)-W^{0}(m, \omega)\right\}, \bar{\kappa}\right\} .
$$

Given this threshold function we can define the value function for an agent at the entrance

\footnotetext{
${ }^{15} \mathrm{We}$ also considered the alternative assumption of measuring as part of GDP the minimum amount of production and trade required for agents to be able to adjust their money holdings to the optimal amount. This did not change any of our results qualitatively and only affected minimally our quantitative results.
} 
of the centralized market (before drawing the fixed cost) as

$$
W(m, \omega)=\int_{0}^{\hat{\kappa}(m, \omega)}\left[W^{1}(m, \omega)-\kappa\right] \frac{1}{\bar{\kappa}} d \kappa+\int_{\hat{\kappa}(m, \omega)}^{\bar{\kappa}} W^{0}(m, \omega) \frac{1}{\bar{\kappa}} d \kappa
$$

or simplifying,

$$
W(m, \omega)=\left[W^{1}(m, \omega)-\frac{\hat{\kappa}(m, \omega)}{2}\right] \frac{\hat{\kappa}(m, \omega)}{\bar{\kappa}}+W^{0}(m, \omega)\left[1-\frac{\hat{\kappa}(m, \omega)}{\bar{\kappa}}\right] .
$$

The fraction of agents participating in the centralized market is given by

$$
f(\omega)=\int_{0}^{\infty} \frac{\hat{\kappa}(m, \omega)}{\bar{\kappa}} \omega(d m)
$$

Also, in equilibrium, choices of money holdings, $m^{\prime}(m, \omega)$, satisfy the money market clearing condition,

$$
\int_{0}^{\infty} \frac{\hat{\kappa}(m, \omega)}{\bar{\kappa}}\left[m^{\prime}(m, \omega)-m\right] \omega(d m)=0
$$

Consider a simple example in which $V$ is concave to illustrate how the centralized market works. Concavity of $V$ implies that $W_{0}$ is a concave function as shown in Figure 2(a). In this example, agents with low money holdings will always choose to pay the fixed cost to sell the general good for liquidity in the centralized market. Also, agents with high money holdings will always choose to pay the fixed cost to purchase the general good in the centralized market. The threshold function is given by the $\hat{\kappa}(m)$ curve in Figure 2(b).

\subsection{The Decentralized Market}

We now consider the bargaining problem of an agent in the decentralized market. Consider a single coincidence meeting when a buyer holds a money balance $m_{b}$ and a seller holds a balance $m_{s}$, after the decentralized market's money injection, when the aggregate state is $\nu$. We assume that the buyer makes a take-it-or-leave-it offer to the seller. That is, he/she 


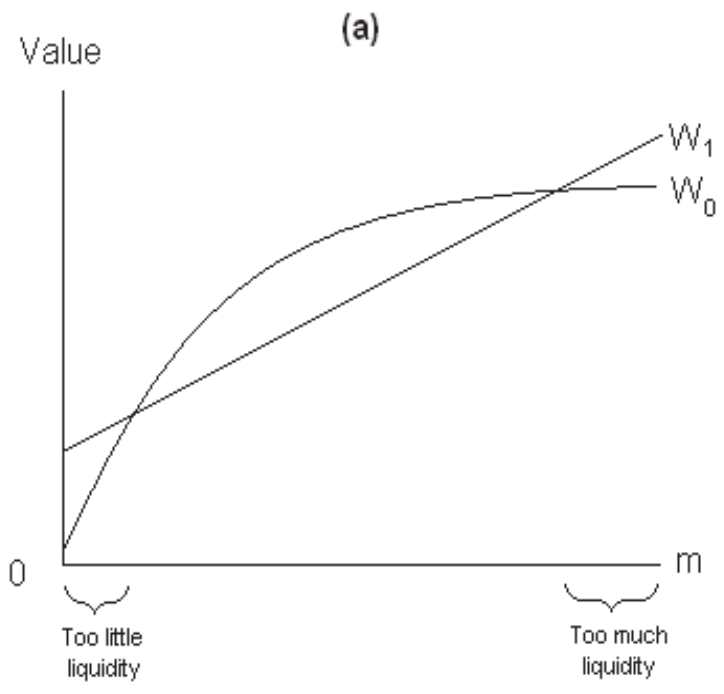

(b)

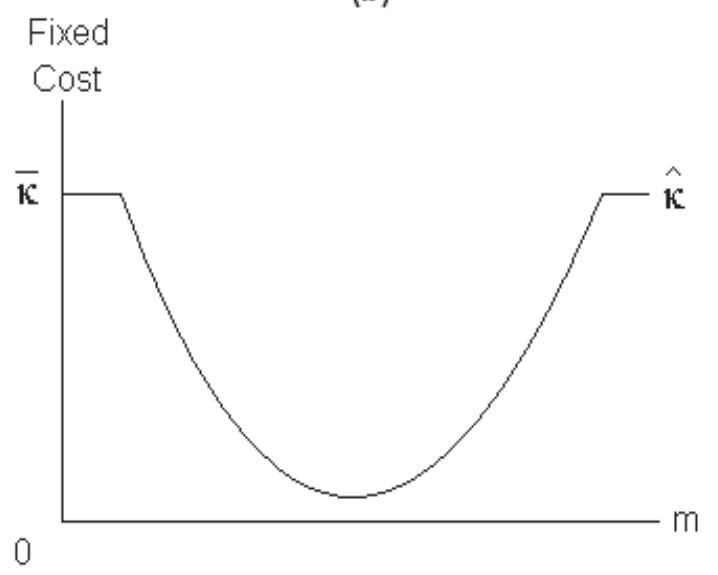

Figure 2: (a) $W_{0}(m, \omega)$ and $W_{1}(m, \omega)$, (b) Threshold Fixed Cost 
proposes a trade of an amount of money, $d$, for a quantity of special good, $q$, that solve the following problem:

$$
\max _{q \geq 0,0 \leq d \leq m_{b}} u(q)+W\left(m_{b}-d, H_{\omega}(\nu)\right)
$$

subject to

$$
-q+W\left(m_{s}+d, H_{\omega}(\nu)\right)=W\left(m_{s}, H_{\omega}(\nu)\right) .
$$

Or, equivalently, by substituting the latter constraint into the objective function,

$$
\max _{0 \leq d \leq m_{b}} u\left[W\left(m_{s}+d, H_{\omega}(\nu)\right)-W\left(m_{s}, H_{\omega}(\nu)\right)\right]+W\left(m_{b}-d, H_{\omega}(\nu)\right) .
$$

The buyer makes an offer to maximize his/her surplus subject to making the seller indifferent between trading and not trading. Note that, given that $W\left(\cdot, H_{\omega}(\nu)\right)$ is a continuous function, the objective function of the bargaining problem is continuous. Also, the set $d \in\left[0, m_{b}\right]$ is non-empty and compact. Thus, by the Theorem of the Maximum and the Measurable Selection Theorem, the set of optimizers is a non-empty, compact-valued, and u.h.c. correspondence and admits a measurable selection. Define $d\left(m_{b}, m_{s}, \nu\right)$ to be such a selection. The function $q\left(m_{b}, m_{s}, \nu\right)$ can then be obtained from the seller's participation constraint.

The expected lifetime utility of an agent that enters the period with money balance $m$ (before the decentralized market money injection) is given by

$$
\begin{aligned}
V(m, \nu)=(1-\sigma) W[m & \left.+\tau(m, \nu), H_{\omega}(\nu)\right]+\sigma \int_{0}^{\infty}\left\{u\left[q\left(m+\tau(m, \nu), m_{s}, \nu\right)\right]\right. \\
& \left.+W\left\{m+\tau(m, \nu)-d\left[m+\tau(m, \nu), m_{s}, \nu\right], H_{\omega}(\nu)\right\}\right\} \nu\left(d m_{s}\right) .
\end{aligned}
$$

The first term is the value for an agent that either is a seller, with probability $\sigma$, and thus has a zero net surplus from trade, or meets no one, with probability $1-2 \sigma$. The second term is the expected value of being a buyer. 


\subsection{Laws of Motions}

Before defining a recursive equilibrium for this economy, we describe the laws of motion $\nu^{\prime}=H_{\nu}(\omega)$ and $\omega=H_{\omega}(\nu)$. We begin by describing the evolution of the aggregate state from the beginning of the centralized market to the beginning of the next decentralized market, $H_{\nu}$. Define the function $\Pi: \mathbb{R}_{+} \times \mathfrak{B}_{\mathbb{R}_{+}} \rightarrow[0,1]$ to be

$$
\Pi(m, B ; \omega)= \begin{cases}1-\frac{\hat{\kappa}(m, \omega)}{\bar{\kappa}}, & \text { if } \frac{m}{\mu} \in B \text { and } m^{\prime}(m, \omega) \notin B ; \\ \frac{\hat{\kappa}(m, \omega)}{\bar{\kappa}}, & \text { if } \frac{m}{\mu} \notin B \text { and } m^{\prime}(m, \omega) \in B ; \\ 1, & \text { if } \frac{m}{\mu} \in B \text { and } m^{\prime}(m, \omega) \in B ; \\ 0, & \text { otherwise. }\end{cases}
$$

Given that, for each $m, \Pi(m, \cdot ; \omega)$ is a probability measure on $\left(\mathbb{R}_{+}, \mathfrak{B}_{\mathbb{R}_{+}}\right)$, and, for each $B \in \mathfrak{B}_{\mathbb{R}_{+}}, \Pi(\cdot, B ; \omega)$ is a $\mathfrak{B}_{\mathbb{R}_{+}}$-measurable function, $\Pi$ is a well defined transition function. Then, the law of motion $H_{\nu}(\cdot)$ can be defined as

$$
\nu^{\prime}(B)=H_{\nu}(\omega)(B) \equiv \int_{0}^{\infty} \Pi(m, B ; \omega) \omega(d m) \forall B \in \mathfrak{B}_{\mathbb{R}_{+}} .
$$

We now describe the evolution of the aggregate state from the beginning of the decentralized market to the beginning of the centralized market. Let $T=\{$ buyer, seller, neither $\}$ and define the space $(T, \mathfrak{T})$, where $\mathfrak{T}$ is the $\sigma$-algebra. Define the probability measure $\psi: \mathfrak{T} \rightarrow[0,1]$, with $\psi($ buyer $)=\psi($ seller $)=\sigma$, and $\psi($ neither $)=1-2 \sigma$. Then, $(T, \mathfrak{T}, \psi)$ is a measure space. Define an event to be a pair $e=(t, m)$, where $t \in T$ and $m \in \mathbb{R}_{+}$. Intuitively, $t$ denotes an agent's trading status and $m$ the money holdings of his current trading partner. Let $(E, \mathfrak{E})$ be the space of such events, where $E=T \times \mathbb{R}_{+}$and $\mathfrak{E}=\mathfrak{T} \times \mathfrak{B}_{\mathbb{R}_{+}}$. Furthermore, let $\xi: \mathfrak{E} \rightarrow[0,1]$ be the product probability measure. Define the mapping 
$\gamma(m, e): \mathbb{R}_{+} \times E \rightarrow \mathbb{R}_{+}$, where

$$
\gamma(m, e)= \begin{cases}m+\tau(m, \nu)-d\left[m+\tau(m, \nu), \cdot H_{\omega}(\nu)\right], & \text { if } e=(\text { buyer }, \cdot) \\ m+\tau(m, \nu)+d\left[\cdot, m+\tau(m, \nu), H_{\omega}(\nu)\right], & \text { if } e=(\text { seller }, \cdot) \\ m+\tau(m, \nu), & \text { otherwise }\end{cases}
$$

We can now define $P: \mathbb{R}_{+} \times \mathfrak{B}_{\mathbb{R}_{+}} \rightarrow[0,1]$ to be

$$
P(m, B ; \nu) \equiv \xi(\{e \in E \mid \gamma(m, e) \in B\})
$$

Again, $P$ is a well defined transition function. ${ }^{16}$ Then,

$$
\omega(B)=H_{\omega}(\nu)(B) \equiv \int_{0}^{\infty} P(m, B ; \nu) \nu(d m) \forall B \in \mathfrak{B}_{\mathbb{R}_{+}}
$$

Finally, we can describe the law of motion of the aggregate state over the two markets as

$$
\left.\nu^{\prime}(B)=H(\nu)(B) \equiv \int_{0}^{\infty} \int_{0}^{\infty} \Pi\left[\bar{m}, B ; H_{\omega}(\nu)\right] P(m, d \bar{m} ; \nu)\right] \nu(d m) \forall B \in \mathfrak{B}_{\mathbb{R}_{+}} .
$$

\subsection{Recursive Equilibrium}

We are finally ready to define a recursive equilibrium for this economy.

Definition 1 (Recursive Equilibrium) A recursive equilibrium is a list of:

Pricing function: $\phi: \Lambda \rightarrow \mathbb{R}_{+} \backslash\{0\}$;

Monetary Policy Function: $\tau: \mathbb{R}_{+} \times \Lambda \rightarrow \mathbb{R}$;

Law of motion: $H: \Lambda \rightarrow \Lambda$;

Value functions: $V: \mathbb{R}_{+} \times \Lambda \rightarrow \mathbb{R}$ and $W: \mathbb{R}_{+} \times \Lambda \rightarrow \mathbb{R}$;

Policy functions: $X: \mathbb{R}_{+} \times \Lambda \rightarrow \mathbb{R}_{+}, Y: \mathbb{R}_{+} \times \Lambda \rightarrow \mathbb{R}_{+}$, and $m^{\prime}: \mathbb{R}_{+} \times \Lambda \rightarrow \mathbb{R}_{+}$;

Terms of Trade: $q: \mathbb{R}_{+} \times \mathbb{R}_{+} \times \Lambda \rightarrow \mathbb{R}_{+}$and $d: \mathbb{R}_{+} \times \mathbb{R}_{+} \times \Lambda \rightarrow \mathbb{R}_{+}$;

\footnotetext{
${ }^{16}$ By construction, for each $m, P(m, \cdot ; \nu)$ is a probability measure on $\left(\mathbb{R}_{+}, \mathfrak{B}_{\mathbb{R}_{+}}\right)$. Furthermore, given the measurability of $d(\cdot, \cdot ; \nu), P(\cdot, B ; \nu)$ is a $\mathfrak{B}_{\mathbb{R}_{+}}$-measurable function.
} 
such that:

1. given the pricing function, the monetary policy functions, the law of motion, the terms of trade, and the policy functions, the value functions satisfy the functional equations (2-5) and (8);

2. given the value functions, the pricing function, the monetary policy functions, and the law of motion of the aggregate state, the policy functions solve (2);

3. given the value functions, the terms of trade solve (7);

4. given the terms of trade and the monetary policy functions, the law of motion of the aggregate state is defined by (10);

5. given the value functions, the monetary policy functions satisfy (1);

6. the centralized market clearing condition, (6), is satisfied.

In the remainder of the paper we will only focus on stationary equilibria, where, $\nu=H(\nu)$.

\section{Numerical Algorithm}

In this section we briefly present the numerical algorithm developed for finding stationary monetary equilibria of the model and discuss some computational considerations. The basic strategy of the algorithm is to iterate on a mapping defined by the value function equations (5) and (8) and the law of motion of the aggregate state given by equation (10). Special care is taken in keeping track of the distribution of wealth and its composition across iterations. In particular, we keep track of a large sample of agent's money balance and use non-parametric density estimation methods. A Fortran 90 version of the code is available from the authors by request. We begin the algorithm at the entrance of the centralized market.

A brief description of the algorithm follows:

Step 1. Given an initial guess for the distribution of money holding at the entrance of the centralized market, draw a large sample of agent's money balance. ${ }^{17}$

\footnotetext{
${ }^{17}$ In all the numerical exercises we use a sample of 10,000 agents.
} 
Step 2. Define a grid on the state space of money holdings and an initial guess for the value function at the entrance of the decentralized market, $V^{0}(m)$, by defining the value of the function at the gridpoints and using interpolation methods to evaluate the function at any other point. ${ }^{18}$

Step 3. Given the sample of money holding at the entrance of the centralized market and the value function at the entrance of the decentralized market, find the market clearing price and participation rate by solving the centralized market problem (4) for all agents in the sample and iterating on $\phi$ and $f$, given an initial guess, until the market clears.

Step 4. Given these, the function $W($.$) is given by (5) .$

Step 5. Given the market clearing price, update the money holding of the agents by solving their optimization problem. The distribution of money holding at the decentralized market is estimated using Gaussian kernel non-parametric density estimation methods. ${ }^{19}$

Step 6. Given the value function $\mathrm{W}($.$) and the distribution of money holdings at the$ entrance of the decentralized market, update the value function $V(m)$ by using the mapping defined by equation (8) to compute its value at the new gridpoints and re-estimating the interpolant coefficients.

Step 7. For each individual on the sample, update their money holding by simulating their meetings to derive the distribution at the entrance of the centralized market.

Repeat steps 3 to 7 until convergence is achieved.

\footnotetext{
${ }^{18}$ We use a grid of 30 gridpoints unevenly spread so as to capture well the change in concavity of the value function. We experimented with increasing the number and location of the gridpoints without significant quantitative or qualitative implications for our results. An Akima interpolation method from the IMSL fortran routines was used to keep track of all functions.

${ }^{19}$ To deal with the fact that the money holdings choices of the centralized market participants might imply the existence of mass points in the distribution we introduce a very small perturbation (a find-a-penny-losea-penny assumption) in their optimal choice to smooth the distribution allowing the usage of the Gaussian kernel estimation method.
} 


\section{Numerical Results: The U.S. Economy}

In what follows we use the numerical algorithm presented in the last section to find and characterize stationary equilibria of the model. In particular, we characterize the typical features of a stationary equilibrium of the model and illustrate the effects of inflation.

We adopt the following functional form for the utility of consumption in the decentralized market:

$$
u(q)=\frac{(q+b)^{1-\eta}-b^{1-\eta}}{1-\eta}
$$

Our objective is to parameterize the model in order to match the velocity of money (or alternatively, the demand for money) implied by the data. Note however that, in the model, the velocity of money is affected by several parameters. In particular, it is affected by the utility function's curvature parameter $\eta$, by the arrival rate $\sigma$, the choice of the length of a period (or equivalently, $\beta$ ), and the fraction of agents that participate in the liquidity market (and thus on the fixed cost). Furthermore, most of these parameters are not observable. In the absence of other clear targets, the parameters are not perfectly identifiable from the data. As such, in the exercises that follow we fix some of the parameters. For the exercises below we set $b \simeq 0$ and $\eta=0.99$, and thus the utility function is close to $\log$. We define the length of a period to be two weeks and set the discount factor to $\beta=0.9983$ implying an annual real interest rate of 4 percent. Given the length of the period, we choose $\sigma$ and $\bar{\kappa}$ such that the money demand function matches the U.S. historical data of average M1-GDP ratio. These two parameters allows us to match the average velocity of money and the interest-elasticity of the money demand implied by the data. Table 1 summarizes the parameter values used and Figure 3 shows the data and the model fit.

Per-period velocity is measured by

$$
\sigma \int_{0}^{\infty} \int_{0}^{\infty} d(m, \tilde{m}, \nu) \nu(d m) \nu(d \tilde{m})
$$

We begin by characterizing a stationary equilibrium. Figure (4) shows the participation 
Table 1: Parameter Values

\begin{tabular}{|c|c|}
\hline Parameter & Value \\
\hline \hline$\sigma$ & 0.4 \\
$\beta$ & 0.9983 \\
$b$ & 0.0001 \\
$\eta$ & 0.99 \\
$\bar{\kappa}$ & 0.02 \\
\hline
\end{tabular}

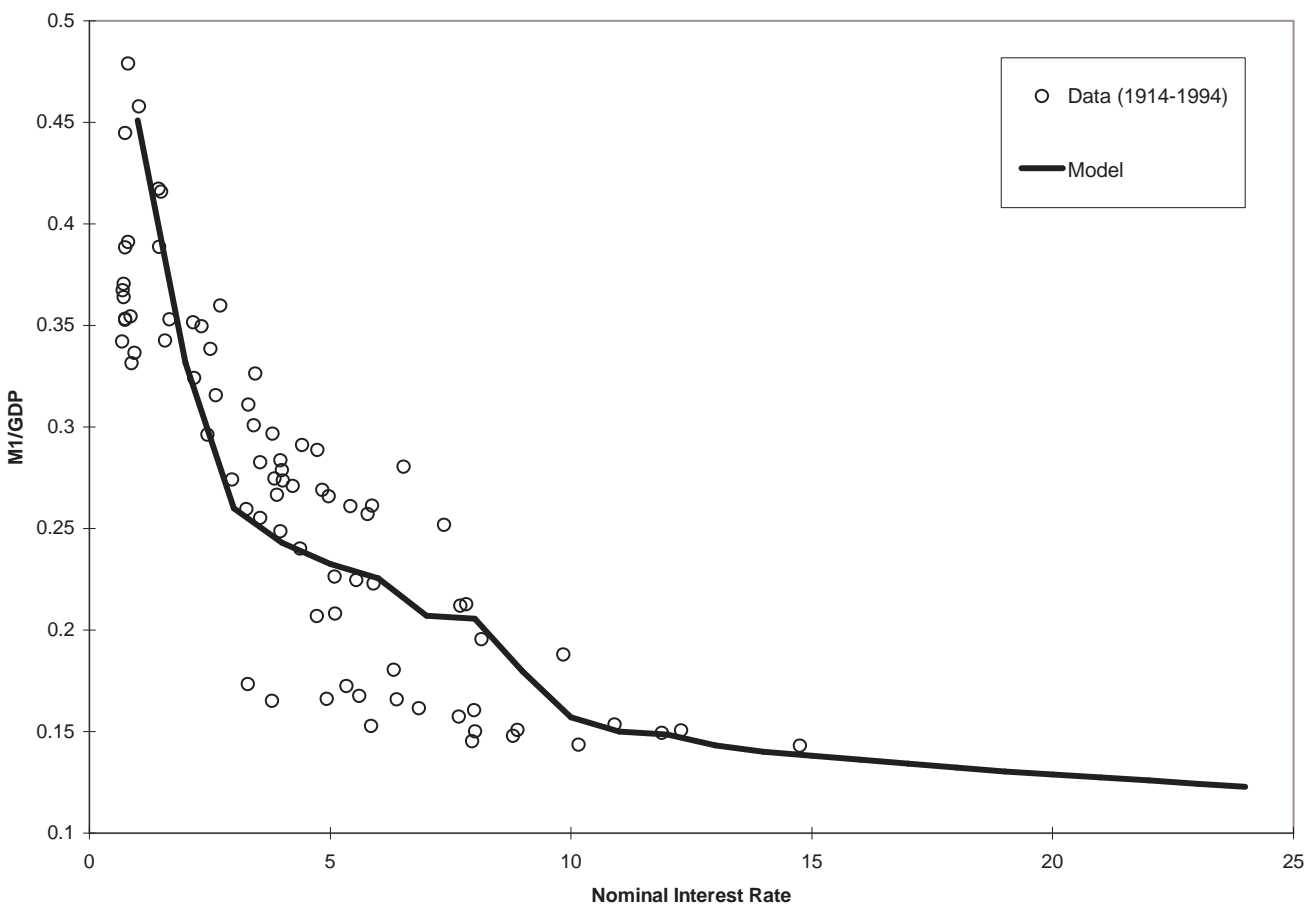

Figure 3: Model vs. US Data 
function and money distribution for the case of zero inflation. The participation function gives the probability with which an agent, with a given money holdings after trade in the decentralized market, will participate in the centralized market. First, note that agents who are poor enough will always choose to participate in the centralized market. Also, for high enough money holdings the probability will converge to one. Given the assumption of linear utility in the centralized market, every agent who participates in the centralized market will choose to bring the same amount of money into the decentralized market. This feature generates the spikes (mass points) of the distribution. Given that not all agents will participate in the centralized market in a given period and the randomness in trading opportunities in the decentralized market, the distribution of money will, in general, be non-degenerate. The discreteness in the choice of whether or not to participate in the centralized market will, in general, imply that the value functions will not be concave, which generates the "wiggles" in the participation function. It is interesting to note that, unlike in Molico(2006), poor agents will choose to spend all their money in the decentralized market. This is due to the fact that in the presence of the liquidity market they do not need to selfinsure by keeping some positive money holdings. In general, in our model the willingness of relatively poor agents to spend money is higher and they will hold less money balances for precautionary motives. This allows us to match the velocity of money in the data which was not possible in Molico since in that environment the only way of insuring was to carry large precautionary money balances. Note also that, for $0 \%$ inflation, agents that re-balance their portfolios will bring into the decentralized market approximately enough liquidity for two purchases.

We now consider the effects of inflation on the stationary monetary equilibrium. Table 2 reports the outcome of the stationary equilibrium for annualized inflation rates of $-2 \%$, $0 \%, 2 \%, 10 \%$, and $20 \%$. With higher inflation, the price of money in terms of the general good in the centralized market, in general, goes down. Agents choose to economize on their money holdings by participating in the liquidity market more frequently, leading to a 

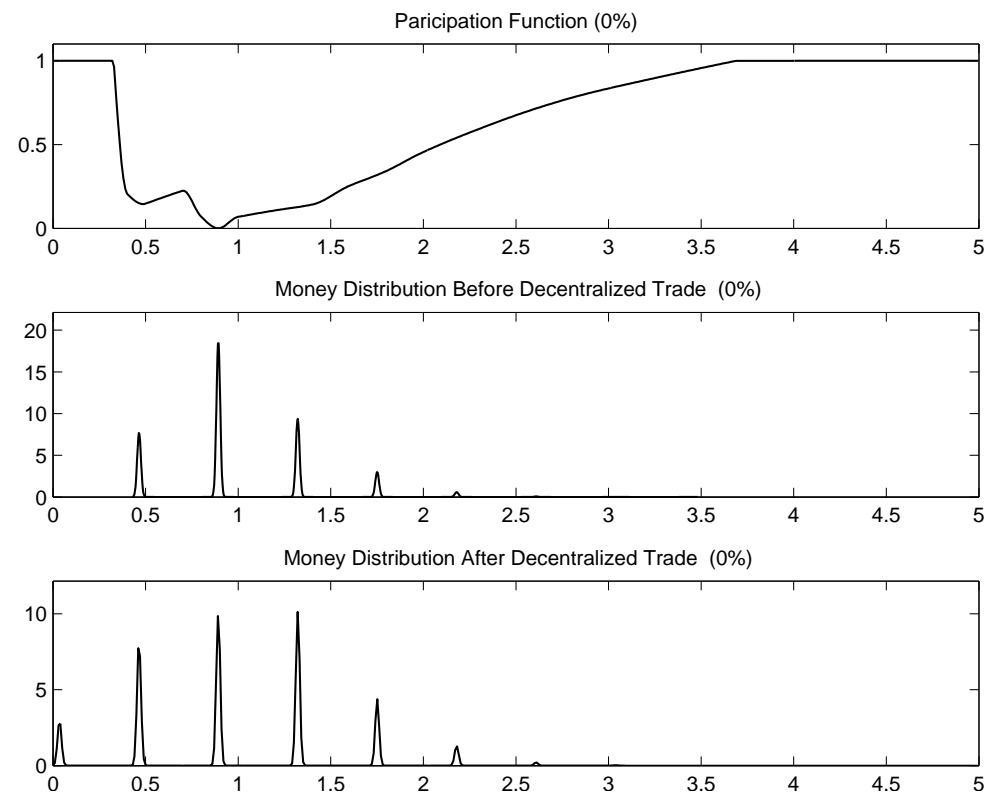

Figure 4: Participation Function and Money Distribution (0\% inflation)

higher participation rate. As a result, the velocity of money rises and the total fixed cost of participation increases.

Figure (5) plots the effect of money growth on the participation function and money distributions. In general, as the money growth rate increases, the participation function shifts up, and the monetary distribution becomes less heterogenous.

Table 2: Effects of Expansionary Monetary Policy

\begin{tabular}{|l|c|c|c|c|c|c|}
\hline Rate of Inflation & $\mathbf{- 2 \%}$ & $\mathbf{0 \%}$ & $\mathbf{1 \%}$ & $\mathbf{2 \%}$ & $\mathbf{1 0 \%}$ & $\mathbf{2 0 \%}$ \\
\hline \hline Price of Money & 3.17 & 2.33 & 2.22 & 2.16 & 1.34 & 1.16 \\
\hline Participation Rate & $12.21 \%$ & $20.97 \%$ & $21.45 \%$ & $23.29 \% \%$ & $44.40 \%$ & $58.09 \%$ \\
\hline Velocity & 3.01 & 4.12 & 4.30 & 4.44 & 7.15 & 8.14 \\
\hline Total Fixed Cost (\% of GDP) & $0.13 \%$ & $0.28 \%$ & $0.31 \%$ & $0.37 \%$ & $0.91 \%$ & $1.24 \%$ \\
\hline
\end{tabular}

Now we study the welfare effect of monetary expansion. We will measure the welfare cost of inflation by deriving how much consumption agents would be willing to sacrifice to reduce inflation to $0 \%$. Using $\hat{\kappa}_{\mu}, q_{\mu}, d_{\mu}, \nu_{\mu}$ and $\omega_{\mu}$ to denote the functions and distributions in an equilibrium with inflation rate $\mu-1$, we can define the average expected value with inflation rate $\mu-1$ as 

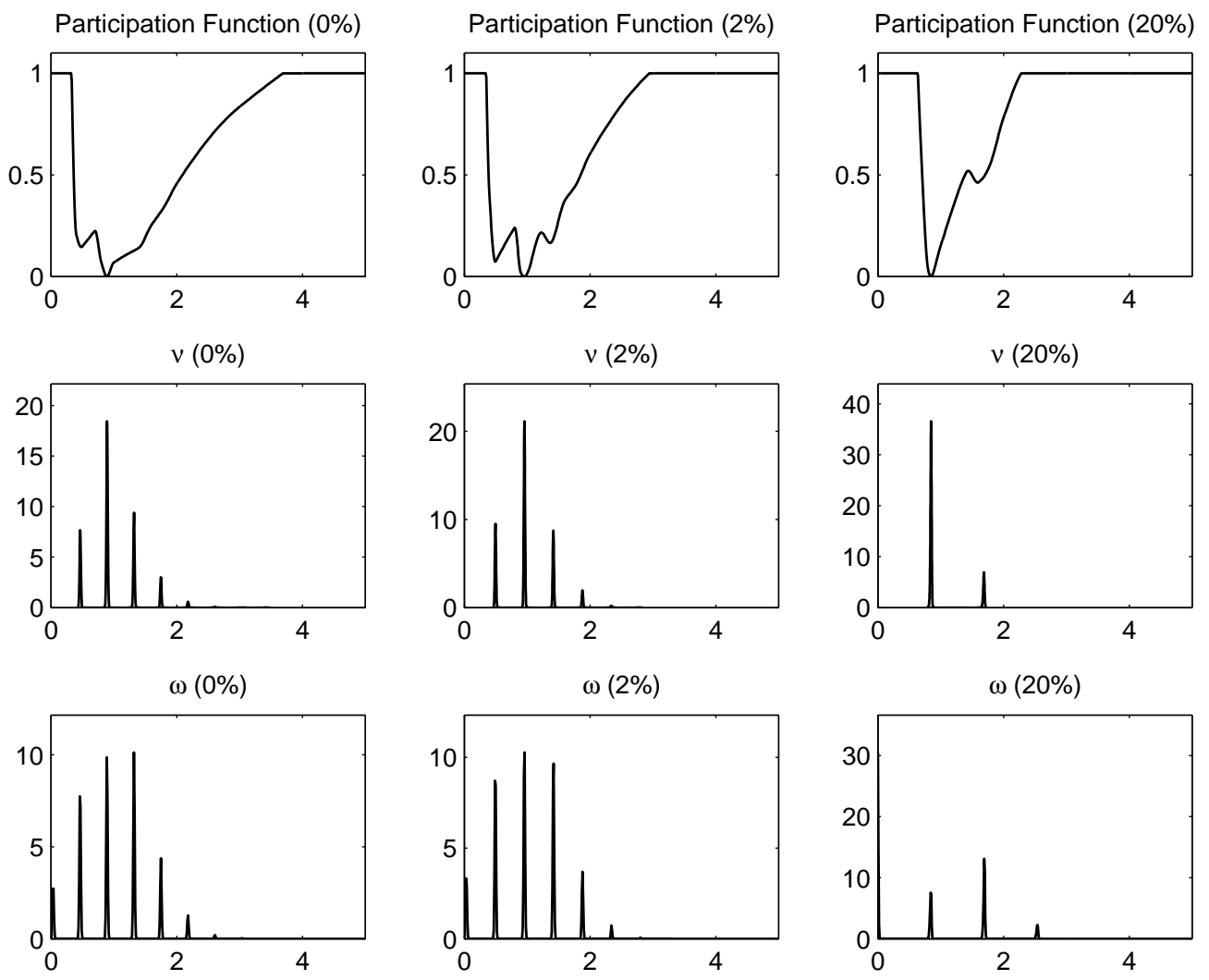

Figure 5: Participation and Distribution for Different Inflation Rates 


$$
\begin{array}{r}
\bar{U}(\mu)=(1-\beta)^{-1}\left\{\sigma \int_{0}^{\infty} \int_{0}^{\infty}\left[u\left(q_{\mu}\left(m, \tilde{m}, \nu_{\mu}\right)\right)-q_{\mu}\left(m, \tilde{m}, \nu_{\mu}\right)\right] \nu_{\mu}(d m) \nu_{\mu}(d \tilde{m})\right. \\
\left.-\int_{0}^{\infty} \frac{\hat{\kappa}_{\mu}\left(m, \omega_{\mu}\right)^{2}}{2 \bar{\kappa}} \omega_{\mu}(d m)\right\} .
\end{array}
$$

Then the welfare cost of having money growth rate $\mu$ relative to zero inflation is given by $1-\Delta_{0}(\mu)$ where $\Delta_{0}(\mu)$ solves

$$
\begin{array}{r}
\bar{U}(\mu)=(1-\beta)^{-1}\left\{\sigma \int _ { 0 } ^ { \infty } \int _ { 0 } ^ { \infty } \left[u\left[q_{0}\left(m, \tilde{m}, \nu_{0}\right) \Delta_{0}(\mu)\right]-\right.\right. \\
\left.-q_{0}\left(m, \tilde{m}, \nu_{0}\right)\right] \nu_{0}(d m) \nu_{0}(d \tilde{m}) \\
\left.-\int_{0}^{\infty} \frac{\hat{\kappa}_{0}\left(m, \omega_{0}\right)^{2}}{2 \bar{\kappa}} \omega_{0}(d m)\right\} .
\end{array}
$$

\section{Distribution and welfare cost of inflation}

First, to focus on a single number, given the parameter values, we find that the welfare cost of $10 \%$ inflation is $1-\Delta_{0}(10 \%)=0.62 \%$ of output, as reported in Table 3 . This number is lower than the estimates of Lucas (around 1\%) and Lagos and Wright (1.3\%) for the same pricing mechanism as we use in this paper. In these representative agent models, the welfare triangle provides an accurate estimate of the true welfare cost. However, in our model, the welfare triangle over-estimates the welfare cost. The reason is that in a heterogenous agent model an expansionary money injection by lump sum transfers redistributes real money balances from the rich to the poor and decreases the dispersion of the monetary distribution. This redistribution effect may raise the average welfare in the economy. Since the aggregate money demand curve captures only the average behavior in an economy, the area under the money demand cannot capture this distributional effect of inflation. Therefore, even abstracting from the hold-up problem pointed out by Lagos and Wright, the traditional approach of estimating welfare cost using aggregate money demand can be misleading. Note however that, inflation also affects the value of money, the terms of trade and the participation in the centralized market, and thus in equilibrium will, generally, 
be welfare decreasing.

Table 3: Gain from reducing inflation from $10 \%$ to $0 \%$

\begin{tabular}{|l|l|c|}
\hline & Model & Welfare Triangle \\
\hline This Model & $0.62 \%$ & $0.85 \%$ \\
$\begin{array}{l}\text { Lagos and Wright (2005) } \\
\text { (No hold-up) }\end{array}$ & $1 \%$ & $1 \%$ \\
\hline
\end{tabular}

Furthermore, in our model, the welfare cost is non-linear in the size of the inflation rate, as illustrated in Figure 6 and Table 4. The welfare cost of a one percent inflation is $0.03 \%$ which is smaller than one-tenth of the welfare cost of a ten percent inflation. Similarly, the welfare cost of a two percent inflation is smaller than one-fifth of a ten percent inflation. The non-linearity in welfare cost reflects the non-linear response of participation to inflation illustrated in Table 2. For example, a one percent inflation raises the participation rate by $1.5 \%$ and the total fixed cost by $0.03 \%$, less than one-tenth of the corresponding numbers for a ten percent inflation (which are $23 \%$ and $0.63 \%$ respectively). In turn, the non-linear response of participation reflects the non-linearity of the distributional wealth effects of inflation. As can be seen from Figure 5, as inflation increases the heterogeneity across agents (dispersion of the money distribution) decreases, leading to smaller distributional wealth effects of inflation. In Lagos and Wright, in the absence of such wealth effects, the welfare cost is linear in the size of inflation. In Lucas, the welfare cost is concave in the size of inflation.

\section{Fixed cost and welfare cost of inflation}

The non-linearity of the welfare cost depends on the size of the fixed cost, $\kappa$. Table 5 reports the welfare costs and participation rates for two percent and ten percent inflation for different values of $\bar{\kappa}$. First, the participation rate is decreasing in the size of the fixed cost and increasing in the rate of inflation. Second, the welfare cost of a ten percent inflation is increasing in the fixed cost while the welfare cost of a two percent inflation is decreasing 


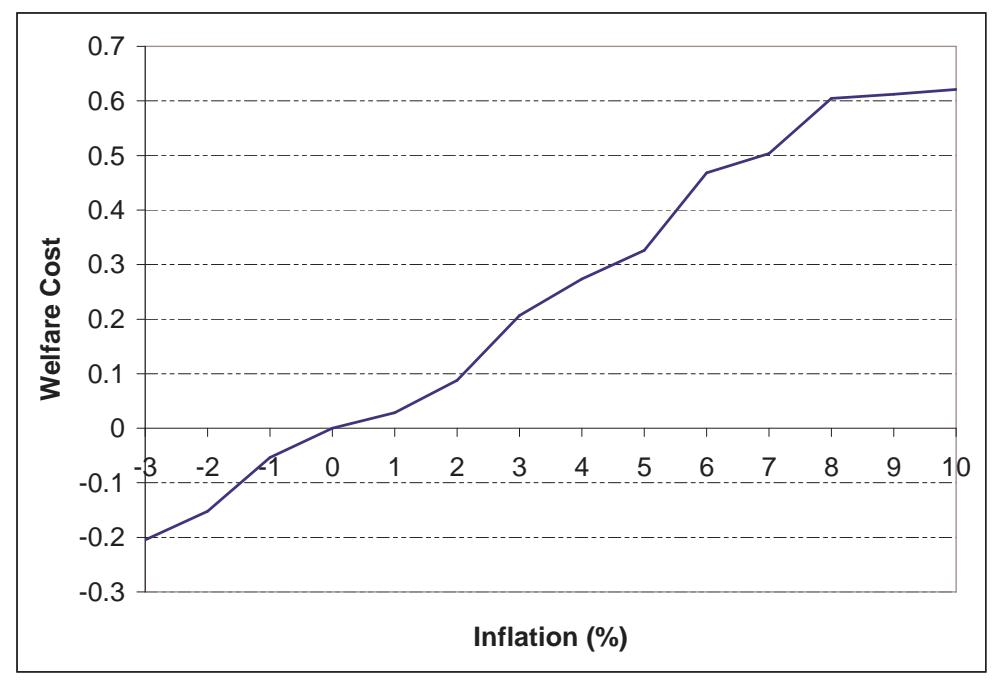

Figure 6: Inflation Rate and Welfare Cost

Table 4: Small inflation less costly in proportional terms

\begin{tabular}{|l|lll|ll|}
\hline Welfare Cost $(W C)$ & $1 \%$ & $2 \%$ & $10 \%$ & $\frac{W C_{1}}{W C_{10}}$ & $\frac{W C_{2}}{W C_{10}}$ \\
\hline This Model & $0.03 \%$ & $0.09 \%$ & $0.62 \%$ & 0.05 & 0.15 \\
Lucas (2000) & $0.12 \%$ & $0.23 \%$ & $0.87 \%$ & 0.14 & 0.26 \\
$\begin{array}{l}\text { Lagos and Wright (2005) } \\
\text { (No hold-up) }\end{array}$ & $0.13 \%$ & $0.26 \%$ & $1.32 \%$ & 0.10 & 0.20 \\
\hline
\end{tabular}

in the fixed cost. The relative size of the welfare costs for different inflation rates depend critically on the sensitivity of the participation rate to inflation. When the fixed cost is relatively small $(\bar{\kappa}=0.01)$, the participation rate is high and responds strongly to a two percent inflation (from $27 \%$ to $39 \%$ ), leading to a relatively large welfare cost $(0.14 \%)$. When the fixed cost is relatively large $(\bar{\kappa}=0.1)$, the participation rate is low and responds less strongly to a two percent inflation (from $7.5 \%$ to $9.0 \%$ ), leading to a relatively small welfare cost $(0.06 \%)$. Again, this can be understood by the variation in the strength of the wealth effects. As Figure 7 illustrates for the case of zero inflation, as the fixed cost increases, fewer agents will participate in the centralized market and consequently the higher the dispersion of the money distribution. This implies that for a higher fixed cost the distributional wealth effects will be stronger for any given rate of inflation. 
Table 5: Fixed cost and welfare cost of inflation

\begin{tabular}{|c|c|c|c|}
\hline & $\mu$ & Welfare Cost & Part. Rate \\
\hline $\bar{\kappa}=\mathbf{0 . 0 1}$ & $0 \%$ & 0 & $27 \%$ \\
& $2 \%$ & 0.1404 & $39 \%$ \\
& $10 \%$ & 0.4089 & $64 \%$ \\
& & $\left(\frac{W C_{2}}{W C_{10}}=0.34\right)$ & \\
\hline $\bar{\kappa}=\mathbf{0 . 0 2}$ & $0 \%$ & 0 & $21 \%$ \\
& $2 \%$ & 0.0854 & $23 \%$ \\
& $10 \%$ & 0.6226 & $44 \%$ \\
& & $\left(\frac{W C_{2}}{W C_{10}}=0.14\right)$ & \\
\hline $\bar{\kappa}=\mathbf{0 . 1}$ & $0 \%$ & 0 & $8 \%$ \\
& $2 \%$ & 0.0610 & $9 \%$ \\
& $10 \%$ & 0.7324 & $15 \%$ \\
& & $\left(\frac{W C_{2}}{W C_{10}}=0.08\right)$ & \\
\hline
\end{tabular}
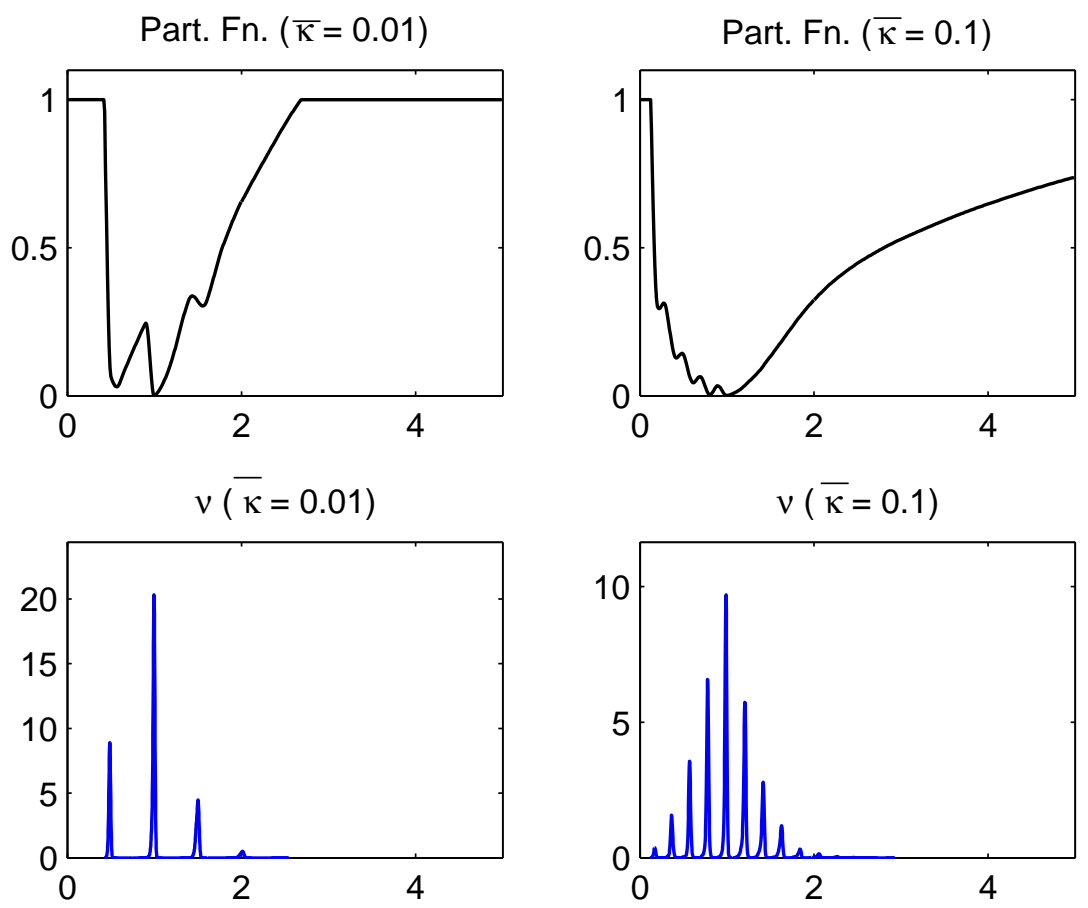

Figure 7: Fixed Cost, Participation Function, and Heterogeneity $(\mu=0)$

A policy implication is that, as the fixed cost decreases overtime (due to financial development, for example), the welfare cost of inflation will be affected. However, the impact on welfare costs of different inflation rates can be completely different both quantitatively and 
qualitatively. In these examples, the welfare cost goes down for high inflation but goes up for low inflation. It would be misleading to use the welfare cost of a ten percent inflation to extrapolate that of a smaller inflation. This considerations are particularly important given that the data suggest there might have been important structural changes to the U.S. aggregate money demand in recent decades. In particular, because such changes might be associated with financial development. Figure 8 illustrates breaks the data points by decade. As can be seen, the aggregate money demand has become flatter overtime, implying a lower interest-elasticity of money demand. This implies that the welfare costs of say, $10 \%$ inflation, for the U.S. economy might actually be smaller than our estimate.

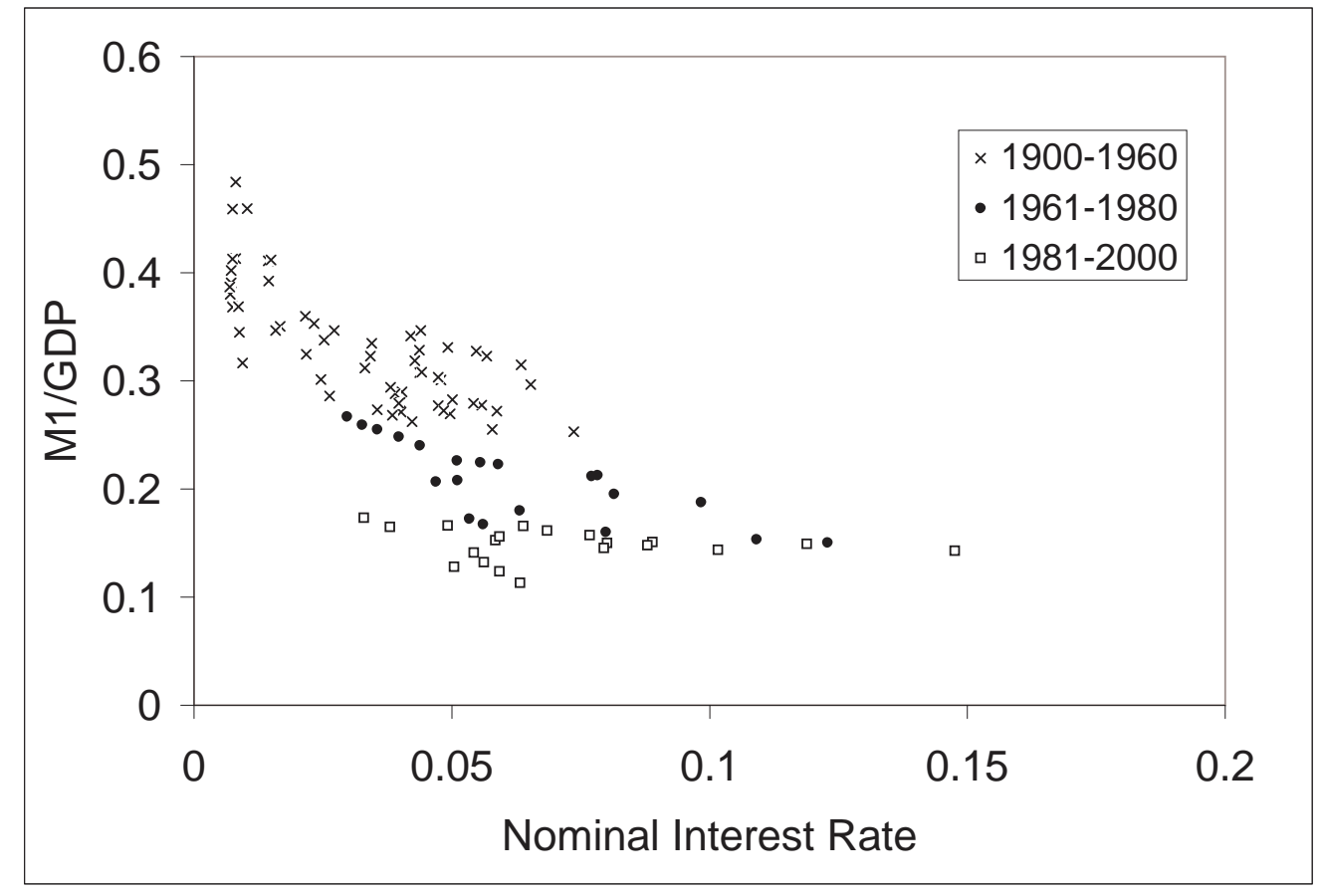

Figure 8: U.S. Money Demand Overtime

\section{The Canadian Economy}

In this section, we redo the above exercise for the Canadian economy. We pick the parameter values to match the empirical money demand for Canada: $\sigma=0.5, \beta=0.9992, \eta=0.99$, 


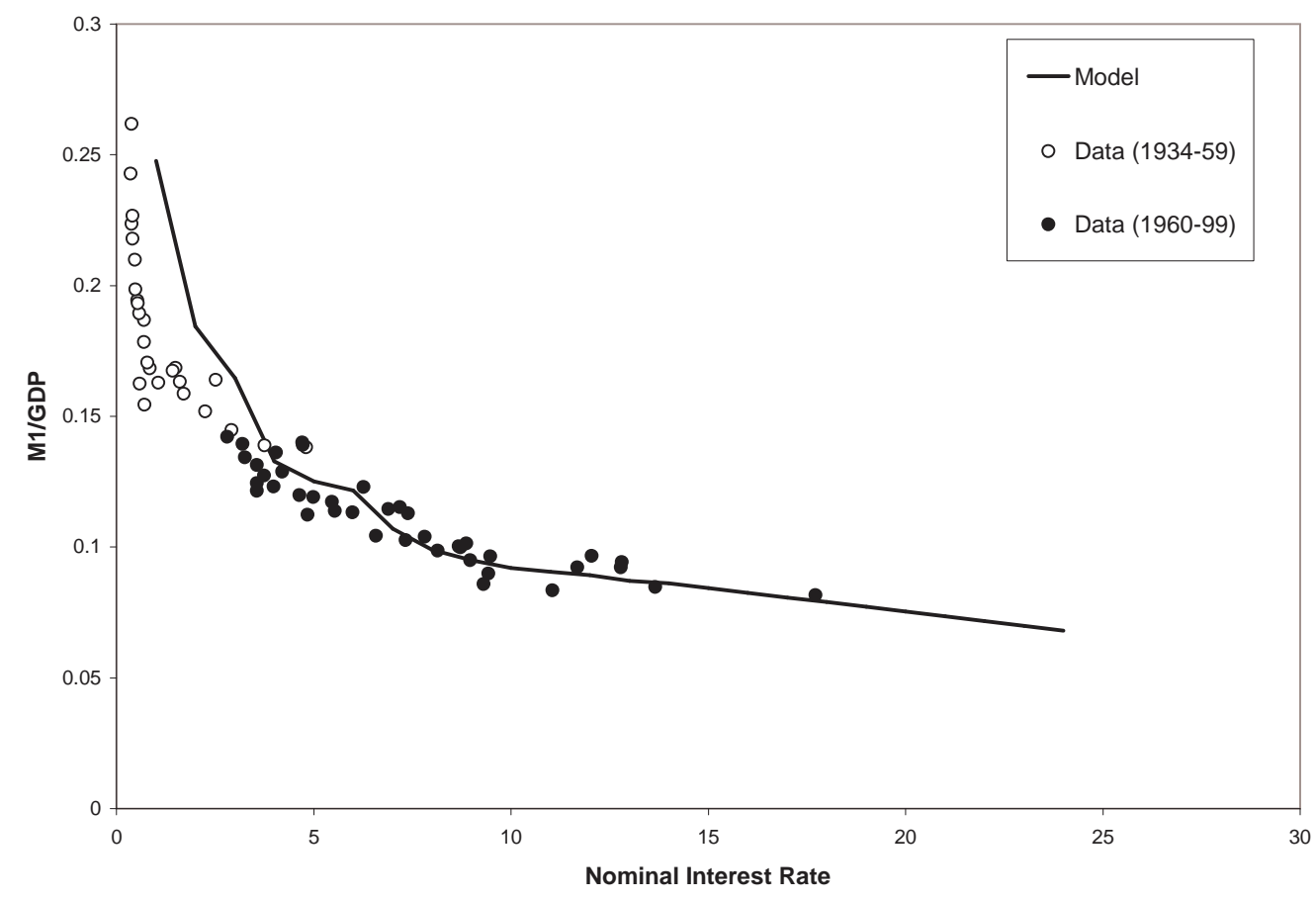

Figure 9: Model vs. Canadian Data

$b=0.0001, \bar{\kappa}=0.04 .^{20}$ Figure 9 plots the Canadian time-series data (1933-99) and the money demand curve implied by the model. The model fits the data points after 1960 better than those before 1960. This might be due to the revision of the Nominal GDP series starting in 1961. But we do not discount the possibility that there was structural shifts of the money demand curve over time. However, for the inflation region of our interest (that is, interest rate over four percent), the demand curve implied by the model does fit the data well.

Table 6 reports the effects of expansionary monetary policy in this economy. The qualitative results are similar to those in the previous section: inflation increases the price of money, the participation rate, the velocity and the total fixed cost. The welfare cost of a ten percent inflation is $0.2 \%$. Again, this is lower than the welfare triangle which is $0.34 \%$. It is worthwhile noticing that the welfare costs of a $10 \%$ inflation for the Canadian economy is one third of that of the U.S. economy. This finding is consistent with previous estimates

\footnotetext{
${ }^{20}$ We use M1 plus bank non-personal notice chequable deposit (post 1968) as the monetary aggregate and the 90 days T-bill auction average yield as the nominal interest rate. M1 estimates prior to 1953 are taken from Metcalf, Redish et al. (1998), post 1953 are taken from CANSIM series V372000. Nominal GDP is obtained from CANSIM series V500633(34-60) and V646937(after 61). The definitions used in the latter series are not consistent and might explain the difficulty of the model in matching the period pre-1961.
} 
Table 6: Effects of Expansionary Monetary Policy

\begin{tabular}{|l|c|c|c|}
\hline Rate of Inflation & $\mathbf{0 \%}$ & $\mathbf{2 \%}$ & $\mathbf{1 0 \%}$ \\
\hline \hline Price of Money & 3.62 & 3.15 & 2.23 \\
\hline Participation Rate & $13 \%$ & $17 \%$ & $26 \%$ \\
\hline Velocity & 7.25 & 8.50 & 11.61 \\
\hline Total Fixed Cost (\% of GDP) & $0.12 \%$ & $0.17 \%$ & $0.32 \%$ \\
\hline Welfare Cost (\% of C) & $0 \%$ & $0.08 \%$ & $0.20 \%$ \\
\hline Welfare Triangle & $0 \%$ & $0.05 \%$ & $0.34 \%$ \\
\hline
\end{tabular}

of the welfare costs of inflation for both economies using a representative agent models and is a reflection of the lower interest-elasticity of the Canadian money demand implied by the data. If one takes into account the recent possible structural changes to the U.S. aggregate money demand such difference might decrease or vanish. Also, the welfare cost is a nonlinear function of the inflation rate. In this case, the welfare cost of a two percent inflation is larger than one-fifth of a ten percent inflation.

\section{Discussion and Conclusion}

This paper develops a micro-founded model to study the effect of inflation on distribution and welfare. By modeling inflation and liquidity market working as alternative insurance mechanisms, this paper illustrates the following findings.

First, distributional effects matter for the welfare. Even without the hold-up problem, measuring welfare cost by aggregate demand function can be misleading. This finding suggests that, knowing the aggregate money demand curve is not sufficient, we need to have the information on the distribution to have an accurate estimate of the welfare effects of inflation. Second, the welfare effect of inflation is nonlinear in the inflation rate. Measuring the welfare cost of inflation by extrapolating high inflation data to unobservable low inflation region can be misleading. Third, the welfare cost of inflation depends on the participation cost of liquidity market. Financial development can affect the welfare cost of different inflation rates differently. 
In terms of policy implications for Canada, our findings suggest that the welfare cost of low inflation (e.g., 2\%) is relatively small. If transition costs are non-trivial, then there might be no welfare gains of reducing the current inflation target further. Also, if there are additional costs of reducing inflation not captured by the model, there might be no gains of reducing the current inflation target.

By focusing on the steady state analysis, we cannot capture the full welfare effect of adjusting inflation rates. To be able to properly measure the potential gain/loss of changing inflation targets one needs to take into consideration the transitional effects and to explicitly solve for the short-run dynamics out of steady state. This interesting but challenging task will be delegated to future research. 


\section{References}

Alvarez, Fernando, Andrew Atkeson and Chris Edmond. (2003). "On the Sluggish Response of Prices to Money in an Inventory-Theoretic Model of Money Demand," NBER Working Paper No. w10016.

Alvarez, Fernando, Andrew Atkeson and Patrick J. Kehoe.(2002). "Money, Interest Rates, and Exchange Rate, with Endogeneously Segmented Markets", Journal of Political Economy 110, 73-112.

Bailey, Martin J. (1956). "The Welfare Cost of Inflationary Finance," Journal of Political Economy 64, 93-110.

Baumol, William J. (1952). "The Transactions Demand for Cash: An Inventory Theoretical Approach," Quarterly Journal of Economics 66, 545-56.

Berentsen, Aleksander, Gabriele Camera and Christopher Waller. (2005). "The Distribution Of Money Balances And The Nonneutrality Of Money", International Economic Review 46, 465-87.

Chiu, Jonathan. (2005). "Endogenously Segmented Asset Market in an Inventory Theoretic Model of Money Demand", mimeo, The University of Western Ontario.

Chiu, Jonathan and Miguel Molico. (2006). "Endogenous Asset Market Participation and Random Matching in an Inventory Model of Money Demand", manuscript.

Deviatov, Alexei and Neil Wallace. (2001). "Another Example in Which Lump-sum Money Creation Is Beneficial," Advances in Macroeconomics 1, Article 1.

Ennis, Huberto. (2005). "Avoiding the Inflation Tax", Working Paper, Federal Reserve Bank of Richmond Working Paper 05-10.

Friedman, Milton. (1969). 'The Optimum Quantity of Money and Other Essays. Chicago: Aldine.

Grossman, Sanford J, and Weiss, Laurence. (1983). "A Transactions-Based Model of the Monetary Transmission Mechanism", American Economic Review 73, 871-80.

İmrohoroğlu, Ayşe. (1992). "The Welfare Cost of Inflation Under Imperfect Insurance," 
Journal of Economic Dynamics and Control 16, 79-91.

Jovanovic, Boyan. (1982). "Inflation and Welfare in the Steady State," Journal of Political Economy 90, 561-77.

Khan, Aubhik and Julia Thomas. (2005). "Inflation and Interest Rates with Endogenous Market Segmentation", manuscript.

Lagos, Ricardo and Randall Wright. (2005). "A United Framework for Monetary Theory and Policy Analysis", Journal of Political Economy 113, 463-484.

Levine, David. (1991). "Asset Trading Mechanisms and Expansionary Policy," Journal of Economic Theory 54, 148-64.

Lucas, Robert. (2000). "Inflation and Welfare", Econometrica 68, p. 247-274.

Metcalf, Cherie, Angela Redish, and Ronald Shearer. (1998). "New Estimates of the Canadian Money Stock, 1987-1967," The Canadian Journal of Economics 31, 104-124.

Molico, Miguel. (2006). "The Distribution of Money and Prices in Search Equilibrium", International Economic Review 47, 701-722.

Romer, David. (1986). "A Simple General Equilibrium Version of the Baumol-TobinModel," Quarterly Journal of Economics 101, 66385.

Serletis, Apostolos, and Kazem Yavari. (2004). "The Welfare Cost of Inflation in Canada and the United States," Economic Letters 84, 199-204.

Tobin, James. (1956). "The Interest-Elasticity of Transactions Demand for Money," Review of Economics and Statistics 38, 241-47.

Telyukova, I. and R. Wright. (2005). "A Model of Money and Credit, with Application to the Credit Card Debt Puzzle", University of Pennsylvania working paper.

Williamson, Stephen. (2006). "Search, Limited Participation, and Monetary Policy", International Economic Review 47, 107-128. 